\title{
UVC disinfection robot
}

\author{
Moez Guettari ${ }^{1}$ • Ines Gharbi ${ }^{2} \cdot$ Samir Hamza ${ }^{3}$
}

Received: 4 June 2020 / Accepted: 7 October 2020 / Published online: 14 October 2020

(C) Springer-Verlag GmbH Germany, part of Springer Nature 2020

\begin{abstract}
The aim of the present work is to contribute in the fight against the spread of Covid-19, a novel human coronavirus, in hospitals, public transport, airlines, and any enclosed areas. In this study, we have adopted the physical disinfection method by using UVC light as agent. The UVC devices are studied and classified according their disinfectant units, complementary devices, combined disinfection agents, mobilities, and order types. Our finding shows that a mobile robot is the most efficient device to inactivate microorganisms, so we have developed a robot called i-Robot UVC. The robot is equipped with eight UVC lamps around a central column and two lamps on the top. The column is fixed on a mobile base where several sensors are integrated to measure temperature and humidity on the one hand, and on the other, to detect motion plus position and to avoid obstacles. The robot can estimate automatically the disinfection time while monitored by Wi-Fi connection from a phone or a tablet. I-Robot UVC disinfects rooms and equipment with ultraviolet light, and shuts down when humans are around to keep them safe. The robot can kill 99,999\% bacteria and various through UVC lamps led. The innovative robot UVC was patented under the number TN2020/0063.
\end{abstract}

Keywords Covid-19 $\cdot$ Disinfection $\cdot$ Hospitals $\cdot$ UVC $\cdot$ Robot

\section{Introduction}

The SARS-CoV-2 responsible for the disease known as Covid19 is a virus that is mostly transmitted through aerosols. The pandemic has recently emerged from China with a total of 83.021 confirmed cases of pneumonia around the world (as of June 2, 2020) (www.worldometers.info/coronavirus/). To reduce the pandemic spread of the virus, five measures have been adopted: (1) massive testing, (2) quarantine, (3) disinfection, (4) social distancing, and (5) sanitary measures. The disinfection

Responsible Editor: Lotfi Aleya

Moez Guettari

gtarimoez@Yahoo.fr

1 Preparatory Institute for Engineering Studies of Tunis, LR19RS003Materials and Fluids Laboratory, University of Tunis, 1089 Tunis, Tunisia

2 Faculté des Sciences de Tunis, LR99ES16- Physique de la Matière Molle et de la Modélisation Electromagnétique, Université de Tunis El Manar, 2092 Tunis, Tunisia

3 Nanobiotechnology Laboratory (UR17ES22), National Institute of Applied Sciences and Technology, North Urban Center, Carthage University, 1080 Tunis, Tunisia techniques are of chemical and/or physical type (Otto et al. 2011). The effectiveness of a disinfection plan depends on the environmental factors such as temperature, relative humidity, organic load, $\mathrm{pH}$, surface topography, water hardness, or the presence of other chemicals compounds (Otto et al. 2011; Mojarad et al. 2017; Darnella et al. 2004). In fact, the agents used in a chemical disinfection procedure are classified according their nature: (1) acids: acetic acid and citric acid; (2) alcohols: ethanol and isopropanol; (3) aldehydes: formaldehyde and gluteraldehyde; (4) alkalis: sodium or ammonium hydroxide, sodium carbonate, and calcium oxide; (5) biguanides: chlorhexidine; (6) halogens: chlorine or iodine compounds; (7) oxidizing agents; and (8) quaternary ammonium compounds. The chemical disinfection of microorganisms refers to the application of a chemical agent at known concentration $\mathrm{C}$. The disinfection phenomenon is a kinetic process described mathematically for the first time by the well-known Chick-Watson model since 1908. The basic rate model of disinfection is described according to the following equation (Chick 1908):

$\frac{d N}{d t}=-k N$

where $N i$ s the number of microorganisms after time $t$ and $k$ is the observed disinfection rate constant. Several authors (Hom 1972; Lambert and Johnston 2000; Prokop and Humphrey 1970) have 
refined the Chick-Watson model by taking account other parameters involved in the disinfection process. Disinfectant concentration and contact time are integral to disinfection kinetics and the practical application of the $\mathrm{Ct}$ concept ( $\mathrm{Ct}$ being the disinfectant concentration multiplied by the contact time). The physical disinfection methods are UV light treatment (Guridi et al. 2019), gamma irradiation treatment (Silindir and Özer 2009), and heat treatment of virus (Sauerbrei and Wutzler 2009). In fact, since 2004, Darnell et al. have examined several methods to inactivate the coronavirus. In this study, the authors have reported that the coronavirus was inactivated by UVC $(254 \mathrm{~nm})$, or at a temperature higher than or equal to $65^{\circ} \mathrm{C}$, alkaline $(\mathrm{pH}>12)$ or acidic $(\mathrm{pH}<3)$ conditions, and formalin and glutaraldehyde treatments.

When UVC is used as a disinfection technique, Equation (1) takes the following form (Kamiko and Ohgaki 1989):

$\frac{d N}{d t}=-Z I N$

where $I\left(\mu \mathrm{W} / \mathrm{cm}^{2}\right)$ and $Z\left(\mathrm{~cm}^{2} / \mu \mathrm{Ws}\right)$ are respectively the UV intensity and the microorganism susceptibility factor. The susceptibility parameters vary with environmental conditions, such as relative humidity (RH) (Ko et al. 2000; McDevitt et al. 2012). It is known that UVC effectiveness decreases with increasing RH (McDevitt et al. 2012). The UVC effectiveness for microorganisms is correlated also to room configuration, lamp placement, lamp age, air movement patterns, and by the mixing degree of room air. The dose relates, $D\left(\mu \mathrm{J} / \mathrm{cm}^{2}\right)$, to the UV intensity according Equation (3):

$D=I t$

where $t(\mathrm{~s})$ is the irradiation time.

The D90 is the required UVC dose for $90 \%$ inactivation of a microorganism. The SARS-CoV-2 is of about $120 \mathrm{~nm}$ in diameter. Its inactivation dose corresponds to $\mathrm{D} 90=6.11 \mu \mathrm{J} /$ $\mathrm{cm}^{2}$ (Jingwen et al. 2020). The virus is highly susceptible to UVC irradiation and its susceptibility is 3 times greater than the influenza (common cold) virus. The dose received by surface unity at given distance $r(\mathrm{~cm})$ from the sanitizer depends on the power, $P(\mu \mathrm{W})$, of the emitted UVC lamp according to the following equation (Owens et al. 2005):

$D=\frac{P t}{2 \pi L r}$

where $L(\mathrm{~cm})$ and $t(\mathrm{~s})$ are, respectively, the length of the lamp and the exposure time, so the exposure time can be estimated according Equation (5):

$t=\frac{2 \pi L r D}{P}$

In order to express the relative number of living microorganisms that are inactivated, the $\log 10$ reduction factor is calculated according the following equation (Mazzola et al. 2003):

$\log 10$ reduction $=\log \left(\frac{N_{0}}{N}\right)$

where $N_{0}$ and $N$ are respectively the number of microorganisms before and after exposure to UV light, so when the $\log 10$ reduction takes the values $1,2,3$, and 4 , the percent reduced microorganisms is respectively $90 \%, 99 \%, 99.9 \%$, and $99.99 \%$.

The medical frameworks are on the front lines of the battle against coronavirus, so the hospitals must be disinfected efficiently and quickly. In this context, the UVC technique is recommended by the scientist community to win the war against the Covid-19 pandemic. In this work, we will firstly present and discuss the different devices using UVC disinfection. Then, we will expose a prototype disinfection robot developed by Tunisian engineers.

\section{UVC devices}

The devices using the UVC technique can be classified as follows: (1) disinfection unit, (2) complementary devices, (3) combined disinfection agents, (4) mobility devices, and (5) order type.

In fact, all devices are manufactured to ensure maximum efficiency and ease of use. The different types of devices will be discussed in the next sections.

\section{Disinfection unit}

Only artificial light sources, the so-called disinfection units, generate radiant energy within the UVC-band. Two main types were distinguished: the lamps and the UVC-LEDs. The lamps are of gas discharge type: mercury, xenon, and xenon-mercury (in small amount).

The UVC-LEDs are semiconductors consisting of stable structure doped in precious metals (Harris et al. 2012; Nyangaresi et al. 2018). The power supply of the sources can be continuous or pulsed, so the light emitted by the sources, the lifetime, and the spectrum emission depends on the nature of source and the power supply type. The conventional UVC lamps, of medium or low pressure, remain the most common disinfection unit source. However, these lamps present inherent disadvantages such as the use of mercury, the low mechanical stability, and ozone production. They are related at $30 \mathrm{~W}$ power and their peak emission was at $254 \mathrm{~nm}$; their lifetime is about 8000 hours. The technology using high-intensity pulsed xenon lamps is a polychromatic source that produces shorttime flashes (Otaki et al. 2003). The lamps are used to generate broad spectrum 200-300 nm high intensity UV light. The 
UVC-LEDs are also emerging UVC light source as an alternative to conventional lamps. The advantage of UVC-LEDs is their compact size and energy saving, which is four to nine times more efficient than the UVC lamps in water treatment. However, their use is still limited as a result of their high cost (Harris et al. 2012; Nyangaresi et al. 2018). Several studies were reported in order to compare the efficiency of the different disinfection units. In fact, McDonald et al. (2000) have compared the decontamination of surfaces and the inactivation of microbe by using conventional lamps and pulsed light sources. They found that pulsed UV light is more effective than conventional lamps. Stibich et al. (2011) have compared the conventional lamps and pulsed xenon systems for the reduction of the healthcare-associated pathogens in hospital rooms. They have shown that pulsed xenon and mercury lamps have the same effectiveness at relatively short exposure time, about $10 \mathrm{~min}$. Song et al. (2020) have used continuous and pulsed xenon UV to inactivate microorganisms in ambulances. They have reported that the device does not need to use chemical agents and reduce $90 \%$ of E. coli, Staphylococcus albus, and environmental pathogens in 30 $\mathrm{min}$. Although the disinfection unit has evolved in the direction of using more compact systems and mercury free, UVC mercury lamps remain the most used thanks to their low cost.

\section{Complementary devices}

In addition to the disinfection unit, UVC-pulsed (continuous) lamps (UVC-LEDs), complementary devices, such as reflective walls and humidifiers, were used to enhance disinfection effectiveness. In this context, several authors (Rutala et al. 2013; Krishnamoorthy and Tande 2014; Sung et al. 2011; Woo et al. 2012) have studied the effect of complementary devices to reduce the disinfection time therefore increasing the effectiveness of UVC lamps. In fact, Rutala et al. (2013) have shown that combining UVC lamps with reflective walls reduce the time necessary to decontaminate a room already contaminated with methicillin-resistant Staphylococcus aureus, from $25 \mathrm{~min} 13 \mathrm{~s}$ to $5 \mathrm{~min} 3 \mathrm{~s}$ and Clostridium difficile spores, from $43 \mathrm{~min} 42 \mathrm{~s}$ to $9 \mathrm{~min} 24 \mathrm{~s}$. Krishnamoorthy and Tande (2014) have shown that employing reflective paint increases from 20 to $10 \%$, depending on the distance sourcesurface, the radiative fluxes on certain surfaces. The experimental results are in agreement with these obtained by mathematical modeling. It has been demonstrated that using humidifiers equally enhances disinfection effectiveness. In fact, Woo et al. (2012) have associated UVC lamps with humidifier using deionized water, beef extract, and artificial salvia, which generates different humidity levels $(30 \%, 60 \%$, and $90 \%)$, in order to examine the relative humidity effect on the disinfection effectiveness of MS2 bacteriophage. A 5.8 logs reduction factor was seen for deionized water at relative humidity of $30 \%$ after applying an UVC lamp $\left(1 \mathrm{~mW} / \mathrm{cm}^{2}\right)$ for $30 \mathrm{~min}$.
McDevitt et al. (2012) have studied the susceptibility of influenza virus to UVC and have reported that it increases with decreasing relative humidity. Complementary devices such as humidifiers and reflective walls are shown to increase the inactivation effectiveness of several microorganisms.

\section{Combined disinfection agents}

Combined disinfectant agents, physical and chemical agents, are being used as emergent technologies in hospitals. The chemical agents include hydrogen peroxide vapor systems and gaseous ozone with mobile UVC lamps. In fact, Anderson et al. $(2017,2018)$ have reported that the addition of UVC disinfection treatment to standard protocol, with chemical agents, had a direct positive effect on the Clostridium difficile and vancomycin-resistant contamination. Haddad et al. (2017) have reported that combining portable xenon-pulsed ultraviolet germicidal light device and standard manual cleaning of surfaces decreases the bacterial load by $70 \%$. Boyce (2016) has recommended the use of newer disinfectants and no-touch decontamination technologies to improve disinfection of surfaces in healthcare. Combined disinfection agents, especially hydrogen peroxide vapor and UVC, allow more effective disinfection.

\section{Mobility devices}

Mahida et al. (2013) have evaluated the Tru-D mobile and automated UVC room decontamination device. They have shown that the device eradicates all the microorganisms with a mean $\log 10$ reduction between three and four when used at $22 \mu \mathrm{J} / \mathrm{cm}^{2}$. This includes a mean of microorganisms percent reduced between 99.9 and $99.99 \%$. The robot was placed in a center position, the device is simple to use and does not require monitoring during decontamination. It operates without the need to deactivate room ventilation or smoke detectors. Tru-D is quicker compared to hydrogen peroxide. Recently, Cadnum et al. (2017) have compared the efficacy of a standard UVC room disinfection device operated in one location and mobile robotics operating in stationary or mobile position. The robot navigates around the patient room to minimize the distance between the device and shadowing. The finding of the authors is that the robotic device operating in a stationary position was as effective as the standard device against organisms in close proximity to the device but significantly less effective at greater distances. However, the UVC robot device programmed to automatically navigate the room is effective in reducing contamination at sites throughout the room. A disinfectant robot is a recent technology used to deactivate microorganisms, but requires a mastery of a set of technologies ranging from robotics, electronics, mechanics, and programming. 


\section{Order type}

Manual disinfection devices are often suboptimal; recently, several mobile and automated room disinfection devices are tested. In fact, Bentancor and Vidal (2018) have presented a remotely programmed device using an Android mobile and an infrared detection security. In fact, the device turns off the lamps when a motion is detected. The robot communicates with the board using Bluetooth devices, thanks to a mobile application, it can be operated from a wide range of Android mobile devices (tablet, cell phone, etc.). The authors have reported the device is effective to eliminate high bacterial inocula and a wide range of microorganisms. The robot does not require use of chemical agents.

\section{I-Robot UVC technology}

Since the discovery of germicidal effects of UVC, research has focused on enhancing the disinfection effectiveness. Recent developments in technology have led to create different types of UVC sources, but UVC germicidal lamps remain the most frequently used due to their relatively low cost. Complementary devices such as humidifiers and wall reflectors decrease disinfection time when used with UVC. Combining disinfectant chemical agents with UVC is an emergent technology but has the disadvantage of damaging hospital material. In the world war against Coronavirus pandemic, robots join medical staff on the front line, especially UVC robot disinfectors. Thanks to the robot's mobility disinfection, time is reduced for an impressive effectiveness without using any complementary devices or chemical agents. Considering the previous studies, a team of Tunisian researchers and engineers has designed and produced a robot disinfector called i-Robot UVC (Fig. 1).

In fact, i-Robot UVC can be controlled manually or run automatically; the robot is designed especially for all areas of hospital and any enclosed space to inactivate microorganisms. The construction of the robot involved: (1) the structural building, (2) the electronic assembling, and (3) the programming of the microcontroller and the mobile application. The structure was made by attaching to a central column two horizontal crows to immobilize eight UVC lamps. Two other lamps are mounted on top of the robot; the system of lamps can cover the space around the device. The central column was placed on a mobile base equipped by a pulse air modulation to avoid excessive lamps warming up. Multiple sensors were integrated on the mobile base to measure temperature and rate humidity. The power supply of the device is done with a direct voltage of $24 \mathrm{~V}$ which supplies energy to the UVC lamps and supplies the Arduino board and the rest of the electronic circuit. The required disinfectant time is estimated according to software by considering the dimension of space, the temperature, and the humidity rate. To measure distance, detect and avoid obstacles, i-Robot UVC is equipped by ultrasound sensor. Infrared sensors permit to detect motion, so the robot operates when people are not around and turns off the UVC lamps otherwise. Thanks to LiDAR sensor, the robot scans the environment and creates a digital map; this permits to optimize intervention. An operator equipped by protective suit controls the robot operation from a dashboard thanks to integrated cameras.
Fig. 1 The UVC disinfection Robot

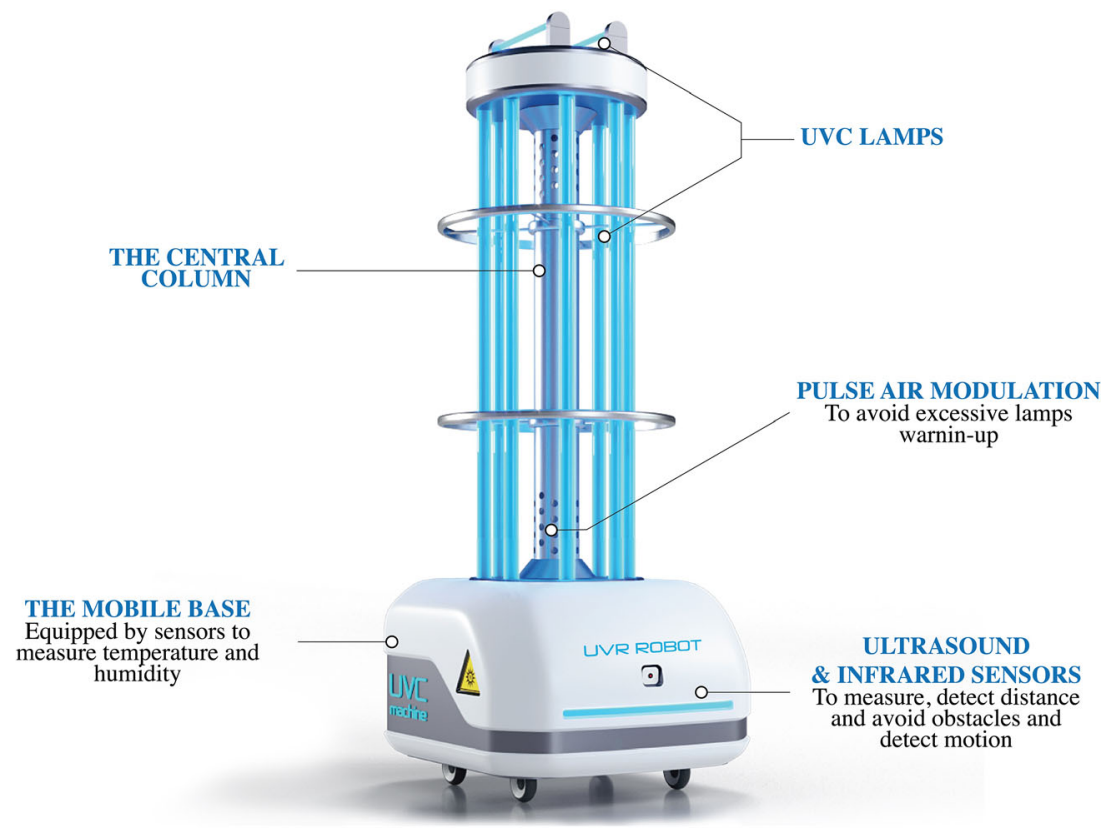




\section{Conclusions}

A contribution of Tunisian research and engineering to the world war against Covid-19 pandemic has been presented in this report. The study of different disinfectant systems led us to identify our choice on the development of a mobile disinfection robot. The iRobot UVC is an autonomous device and can be controlled manually. It can also work in a fully automated mode. The lamps integrated into the robot and its mobility can deactivate coronavirus and microorganisms in a record time. Based on artificial intelligence, integrated sensors, and cameras, the device is of high security. I-Robot UVC shuts down when humans are around to protect them from the harmful effects of UVC.

Authors' contributions Moez Guettari collected and analyzed data. He contributed to the study conception and design of the robot and co-wrote the manuscript. Ines Gharbi has collected and analyzed data. She also contributed to the study conception and design of the robot and cowrote the manuscript. Samir Hamza contributed to the study conception and design of the robot, conceived the robot, and co-wrote the manuscript.

Funding This work is funded by the Ministry of Higher Education and Scientific Research.

\section{Compliance with ethical standards}

Competing interests The authors declare that they have no competing interests.

Ethical approval Not applicable.

Consent to participate The authors have consent to participate.

Consent to publish The authors have consent to publish.

\section{References}

Anderson DJ, Chen LF, Weber DJ, Moehring RW, Lewis SS, Triplett PF, Blocker M, Becherer P, Schwab JC, Knelson LP, Lokhnygina Y, Rutala WA, Kanamori H, Gergen MF, Sexton DJ, CDC Prevention Epicenters Program (2017) The benefits of enhanced terminal room (BETR) disinfection study: a prospective, cluster randomized, multicenter, crossover study to evaluate the impact of enhanced terminal room disinfection on acquisition and infection caused by multidrugresistant organisms. Lancet Infect Dis 389:805-814. https://doi.org/ 10.1016/S0140-6736(16)31588-4

Anderson DJ, Moehring RW, Weber DJ, Lewis SS, Chen LF, Schwab JC, Becherer P, Blocker M, Triplett PF, Knelson LP et al (2018) Effectiveness of targeted enhanced terminal room disinfection on hospital-wide acquisition and infection with multidrug-resistant organisms and Clostridium difficile: a secondary analysis of a multicentre cluster randomised controlled trial with crossover design (BETR Disinfection). Lancet Infect Dis 18:845-853. https://doi.org/ 10.1016/S1473-3099(18)30278-0

Bentancor M, Vidal S (2018) Programmable and low-cost ultraviolet room disinfection device. HardwareX. 4:1-13. https://doi.org/10. 1016/j.ohx.2018.e00046
Boyce JM (2016) Modern technologies for improving cleaning and disinfection of environmental surfaces in hospitals. Antimicrob Resist Infect Control 5:1-10. https://doi.org/10.1186/s13756-016-0111-x

Cadnum J, Piedrahita C, Jencson A, Mathew JI, Donskey CJ (2017) Next-generation UV: evaluation of a robotic ultraviolet-C room. Open Forum Infect Dis 4:S193-S194. https://doi.org/10.1093/ofid/ ofx 163.368

Chick H (1908) An investigation of the laws of disinfection. J Hyg 8:092158

Darnella MER, Subbaraob K, Feinstonea SM, Taylora DR (2004) Inactivation of the coronavirus that induces severe acute respiratory syndrome, SARS-CoV. J Virol Methods 121:85-91. https://doi.org/ 10.1016/j.jviromet.2004.06.006

Guridi A, Sevillano E, De la Fuente I, Mateo E, Eraso E, Quindós G (2019) Disinfectant activity of a portable ultraviolet c equipment. Int J Environ Res Public Health 16:4747-4758. https://doi.org/10. 3390/ijerph16234747

Haddad LE, Ghantoji SS, Stibich M, Fleming JB, Segal C, Ware KM, Chemaly RF (2017) Evaluation of a pulsed xenon ultraviolet disinfection system to decrease bacterial contamination in operating rooms. BMC Infect Dis 17:672-677. https://doi.org/10.1186/ s12879-017-2792-z

Harris TR, Pagan JG and Batoni P (2012) Optical and fluidic co-design of a UV-LED water disinfection chamber. ECS Transactions, 45, 221st ECS Meeting, May 6 - May 10, Seattle, WA, 17

Hom LW (1972) Kinetics of chlorine disinfection in an ecosystem. J Sanit Eng Div Asce 98:183-194

Jingwen C, Li L, Hao W (2020) Review of UVC-led deep ultraviolet killing new NCP coronavirus dose in technology sharing. (Hubei Shenzi Technology Co., Ltd)

Kamiko N, Ohgaki S (1989) Rna coliphage Ob as a bioindicator of the ultraviolet disinfection efficiency. Waf Sci Tech 21:227-231

Ko G, First MW, Burge HA (2000) Influence of relative humidity on particle size and UV sensitivity of Serratia marcescens and Mycobacterium bovis BCG aerosols. Tuber Lung Dis 80:217-228. https://doi.org/10.1054/tuld.2000.0249

Krishnamoorthy G, Tande BM (2014) Improving the effectiveness of ultraviolet germicidal irradiation through reflective wall coatings: experimental and modeling based assessments. Indoor Built Environ:1-15. https://doi.org/10.1177/1420326X14547785

Lambert RJW, Johnston MD (2000) Disinfection kinetics: a new hypothesis and model for the tailing of log-survivor/time curves. J Appl Microbiol 88:907-913

Mahida N, Vaughan N, Boswell T (2013) First UK evaluation of an automated ultraviolet-C room decontamination device (Tru-DTM). J Hosp Infect 84:332-335. https://doi.org/10. 1016/j.jhin.2013.05.005

Mazzola PG, Christina T, Penna V, Da S, Martins AM (2003) Determination of decimal reduction time (D value) of chemical agents used in hospitals for disinfection purposes. BMC Infect Dis $3: 1-10$

Mcdevitt JJ, Rudnick SN, Radonovich L (2012) Aerosol susceptibility of influenza virus to UV-C light. Appl Environ Microbiol 78:16661669. https://doi.org/10.1128/AEM.06960-11

McDonald KF, Curry RD, Clevenger TE, Unklesbay K, Eisenstark A, Golden J, Morgan RD (2000) A comparison of pulsed and continuous ultraviolet light sources for the decontamination of surfaces. Ieee T Plasma Sci 28:1581-1587

Mojarad N, Khalili Z, Aalaei S (2017) A Comparison of the efficacy of mechanical, chemical, and microwave radiation methods in disinfecting complete dentures. Dent Res J (Isfahan) 14:131-136

Nyangaresi PO, Qin Y, Chen G, Zhang B, Lu Y, Shen L (2018) Effects of single and combined UV-LEDs on inactivation and subsequent reactivation of E. coli in water disinfection. Water Res 147:331-341. https://doi.org/10.1016/j.watres.2018.10.014 
Otaki M, Okuda A, Tajima K, Iwasaki T, Kinoshita S, Ohgaki S (2003) Inactivation differences of microorganisms by low pressure $\mathrm{UV}$ and pulsed xenon lamps. BMC Infect Dis 3:1-10. https://doi.org/10. 2166/wst.2003.0193

Otto C, Zahn S, Rost F, Zahn P, Jaros D, Rohm H (2011) Physical methods for cleaning and disinfection of surfaces. Food Eng Rev 3:171-188. https://doi.org/10.1007/s12393-011-9038-4

Owens MU, Deal DR, Shoemaker MO, Knudson GB, Janet E, Deal JL (2005) High-dose ultraviolet $\mathrm{C}$ light inactivates spores of Bacillus subtilis var. niger and Bacillus anthracis sterne on non-reflective surfaces. Appl Biosaf 10:240-247. https://doi.org/10.1177/ 153567600501000406

Prokop A, and Humphrey AE (1970) Kinetics of disinfection. Disinfection ed. New York

Rutala WA, Gergen MF, Tande BM, Weber DJ (2013) Rapid hospital room decontamination using ultraviolet (UV) light with a nanostructured UV-reflective wall coating. Infect Control Hosp Epidemiol 34: 527-529. https://doi.org/10.1086/670211

Sauerbrei A, Wutzler P (2009) Testing thermal resistance of viruses. Arch Virol 154:115-119. https://doi.org/10.1007/s00705-008-0264-x

Silindir M, Özer AY (2009) Sterilization methods and the comparison of E-beam sterilization with gamma radiation sterilization. Fabd J Pharm Sci 34:43-53
Song L, Li W, Li JHL, Li T, Gu D, Tang H (2020) Development of a pulsed xenon ultraviolet disinfection device for real-time air disinfection in ambulances. Hind J Healthc Eng:1-5. https://doi.org/10. 1155/2020/6053065

Stibich M, Stachowiak J, Tanner B, Berkheiser M, Moore L, Raad I, Chemaly RF (2011) Evaluation of a pulsed-xenon ultraviolet room disinfection device for impact on hospital operations and microbial reduction. Infect Control Hosp Epidemiol 32:286-288. https://doi. org/10.1086/658329

Sung M, Kato S, Kim YM, Harada M (2011) Disinfection performance of ultraviolet germicidal irradiation systems for the microbial contamination on an evaporative humidifier. Hvac\&R Res 17:22-30. https://doi.org/10.1080/10789669.2010.541540

Woo MH, Grippin A, Anwar D, Smith T, Wu CY, Wander JD (2012) Effects of relative humidity and spraying medium on UV decontamination of filters loaded with viral aerosols. Appl Environ Microbiol 78:5781-5787. https://doi.org/10.1128/AEM.00465-12

www.worldometers.info/coronavirus/

Publisher's note Springer Nature remains neutral with regard to jurisdictional claims in published maps and institutional affiliations. 